\title{
The severity of driver fatigue in terms of line crossing: a pilot study comparing day- and night time driving in simulator
}

\author{
Anna Anund $^{1,2}$ (D) Carina Fors $^{1} \cdot$ Christer Ahlstrom ${ }^{1}$
}

Received: 28 December 2016 / Accepted: 22 May 2017 /Published online: 30 May 2017

(C) The Author(s) 2017. This article is an open access publication

\begin{abstract}
Introduction The overall aim of this study is to compare daytime driving with night-time driving looking at line crossings during self-reported sleepiness and long blinks. The hypothesis is that high levels of self-reported sleepiness (KSS 9) and long blink duration $(>0.15 \mathrm{~s})$ will be less associated with critical events during the day-time compared to night-time.

Method The study is based on data from a driving simulator experiment with 16 participants driving $150 \mathrm{~km}$ on a typical Swedish motorway scenario twice: once during daytime and once during night time. In total data from 6 segments of $4 \mathrm{~km}$ each equally distributed along the drive was averaged and included in the analysis. A Mixed Model Anova was used to test the effects on KSS, Blink Duration and Line Crossings with factors for Session (Day/Night) and Road segment (1-6), and participant as random. In addition, a logistic regression was used to identify when there is a risk for line crossings. Finally, the proportion of line crossings in relation to high KSS values and long blink durations was tested with Fisher's exact test. Results The results show no differences in the percentage of Line Crossings to the left during high levels of Karolinska Sleepiness Scale during daytime (33\%) compare to night-time
\end{abstract}

Anna Anund

anna.anund@vti.se

Carina Fors

carina.fors@ vti.se

Christer Ahlstrom

christer.ahlstrom@vti.se

1 Swedish National Road and Transport Research Institute (VTI), SE - 58195 Linköping, Sweden

2 Rehabilitation Medicine, Linköping University, SE- 581 85 Linköping, Sweden
(40\%). However, there was a significant difference between day and night time line crossings while the driver had long duration blinks (4\% during daytime and 35\% during night-time). Despite these results the most promising predictor of line crossings in each segment of $4 \mathrm{~km} / \mathrm{h}$ was KSS with an Odds Ratio of 5.4 with a reference value at Karolinska Sleepiness Scale level 5. Conclusion In conclusion, the results do not support the hypothesis that high levels of KSS will result in more frequent line crossings at night time compared to day time. However, the result supports the hypothesis that long blink durations are associated with more line crossings when they appear during night time than during daytime.

Keywords Simulator study $\cdot$ Driver sleepiness $\cdot$ Driver fatigue $\cdot$ Subjective sleepiness $\cdot$ Blink duration $\cdot$ Lane deviations

\section{Introduction}

Driver sleepiness is a contributing factor in many road crashes $[1,2]$. In particular an increased risk has been reported when driving during the night or early morning hours [2-4], for young [5, 6] and for professional [7-9] drivers, shift workers driving home after a night shift $[10,11]$, and for people with untreated sleep disorders [7-9, 12]. In general, driving when sleepy impairs driving performance causing deteriorated lateral (for example keeping the position in the lane) and longitudinal control (for example keeping the speed in a stable state) of the vehicle. With increased levels of sleepiness, these deteriorations become more and more severe and will eventually lead to line crossings and crashes [13].

The terms sleepiness and fatigue are often used synonymously even though the causal factors contributing to the state may differ [14]. The main determinants of sleepiness are the 
time of day (circadian rhythm) and the duration of previous periods of being awake and asleep (homeostatic regulation) $[15,16]$. Fatigue on the other hand may also be due to other factors such as monotony, task demand and task duration [17] and may arise in the absence of sleep-related causes. Sleepiness and fatigue are intertwined and it is difficult to isolate one from the other.

A common approach when studying driver sleepiness is to use sleep deprived drivers [18-20]. Usually, the drivers are in an alert condition during daytime and in a sleep deprived condition during night-time. One consequence of such a study design is that there is a confounding effect between the sleeprelated factor day versus night (circadian effect) and between the factor alert versus sleep deprived (homeostatic effect) [21]. In addition, there is also an effect of fatigue-related factors such as time on task and boredom. The consequences of driving under this mixture of causal factors are heavily understudied in the research literature. For example, is a driver more likely crash during the night-time compared to daytime, when the sleepiness level being experienced is the same in the two conditions?

The overall aim of this study is to compare day-time driving with night-time driving looking at line crossings during self-reported sleepiness and long blinks The hypothesis is that high self-reported sleepiness (KSS 9) and long blink duration $(>0.15 \mathrm{~s})$ will be less associated with critical events during the daytime compared to night time.

\section{Method}

\subsection{Participants and procedure}

A total of 16 participants ( 8 men) aged 30-60 years old were recruited from the Swedish National Register of vehicle owners. The subjects were compensated 3000 SEK for their participation. Approximately two weeks before the experiment started the participants received detailed information about the coming experiment together with sleep and wake diaries that were to be filled in the three nights and two days immediately prior to the experimental day. They also received background questionnaires. In addition, the scale to use for reporting self-reported sleepiness (KSS) was sent home together with an instruction of how to train before the arrival.

The study was ethically approved by the regional ethical committee in Linköping, registration number 2010/153-3.

\subsection{Platform}

An advanced moving base driving simulator with a cabin of a Saab 9-3, 120 degrees forward field of view and an automatic gearbox was used to simulate driving on a motorway, see Fig. 1.

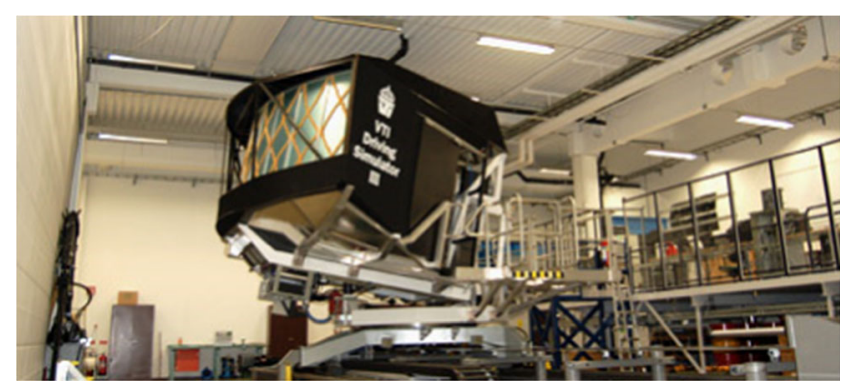

Fig. 1 VTI driving simulator III

\subsection{Scenario and design}

A Swedish motorway with a normal speed limit of $110 \mathrm{~km} / \mathrm{h}$ was used as a test route. The route was a replicate of the E4 between Linköping and Jönköping, driving on the right side. In the beginning of the drive there were three overtaking events where the test driver was supposed to overtake slow vehicles. This was to increase the realism, in addition every $7 \mathrm{~min}$ a car overtook the test driver. Half-way through the test route, the posted speed limit was changed to $90 \mathrm{~km} / \mathrm{h}$ for $1 \mathrm{~km}$, because there was a similar change of speed on the real road simulated. The total length of the simulator test route was about $150 \mathrm{~km}$ and it took approximately $75-80 \mathrm{~min}$ to drive. The subjects were instructed to drive as they would do in "real life". They were not allowed to speak, listen to the radio or do anything else that would counteract their sleepiness. The first part of the driving was used for familiarization with the simulator.

Each participant completed two driving sessions on the test occasion for practical reasons: the first was an alert condition and the second was a sleepy condition, see Table 1 . The first started to drive at 15:30 (day) and at 00:15 (night), while the second started to drive at 17:45 and 02:45. The participants arrived by them self and were sent home in the end of the night by taxi.

\subsection{Measures and data structure}

In order to control for the effect of time on task but avoid confounding results during overtaking, passing situations and change in speed limits, fixed road segments along the road way were selected for the analysis, see Table 2 . Road segment is used as a factor for time on task.

The sampling frequency of simulator data was $10 \mathrm{~Hz}$ for all signals.

The measures speed, lateral position, steering behaviour, and brake were stored. In this study we only use lateral position to calculate when the driver hit the line on the left side, with wheels on the right side of the car. Based on this the average number of line crossings per segment $(4 \mathrm{~km}$ road driven) was calculated. Line crossings is a measure that is as close as we can come to critical situations and commonly used 
Table 1 Start and end times for the driving sessions

\begin{tabular}{lll}
\hline & Start & End \\
\hline Firs Participant Day & $15: 30$ & $17: 15$ \\
Second Participant Day & $17: 45$ & $19: 30$ \\
First participant Night & $00: 15$ & $02: 00$ \\
Second Participant Night & $02: 45$ & $04: 30$ \\
\hline
\end{tabular}

$[22,23]$. The reason left crossing were selected was based on the fact that the majority of departures were to the left. During each driving session the subjects self-reported their sleepiness level on the 9-grade Karolinska Sleepiness Scale (KSS) every five minutes [24]. The KSS scale has been proven to be a sensitive indicator and is well validated [25].

A Vitaport system (TEMEC Instrument B.V., The Netherlands) was used to record EEG (three channels), EMG (on the jaw) and ECG (lead II) with a sampling frequency of $256 \mathrm{~Hz}$ during the driving sessions. EOG (two vertical and one horizontal channel) was sampled with a frequency of $512 \mathrm{~Hz}$. In this study we only use the EOG based Blink Duration, a commonly used measure of sleepiness [26]. Blink duration was extracted from one of the vertical EOG channels by using an automatic blink detection algorithm [27]. The algorithm low-pass filters the EOG data, calculates the derivative, and searches for sequences where the derived signal exceeds a threshold and falls below another threshold within a short time period. If the amplitude of the original, low-pass filtered EOG signal in such a sequence exceeds a subject specific threshold, the sequence is assumed to be a blink. To reduce problems with concurrence of eye movements and blinks, blink duration was calculated at half the amplitude of the.

\subsection{Statistical analysis}

The analysis is based on averaged data of the $4 \mathrm{~km}$ road driven for each of the 6 segments. Mixed model ANOVAs (alpha $=0.05)$ was used to test the effects on KSS, Blink Duration and line crossings with factors for Session (Day/ Night) and Road Segment (1-6). The model included interactions and Participant was used as a random factor.

Table 2 Selection of road segments $(\mathrm{km})$ for the analysis

\begin{tabular}{lll}
\hline Road segment & Start $(\mathrm{km})$ & End $(\mathrm{km})$ \\
\hline 1 & 14 & 18 \\
2 & 32 & 36 \\
3 & 50 & 54 \\
4 & 68 & 72 \\
5 & 86 & 90 \\
6 & 104 & 108 \\
\hline
\end{tabular}

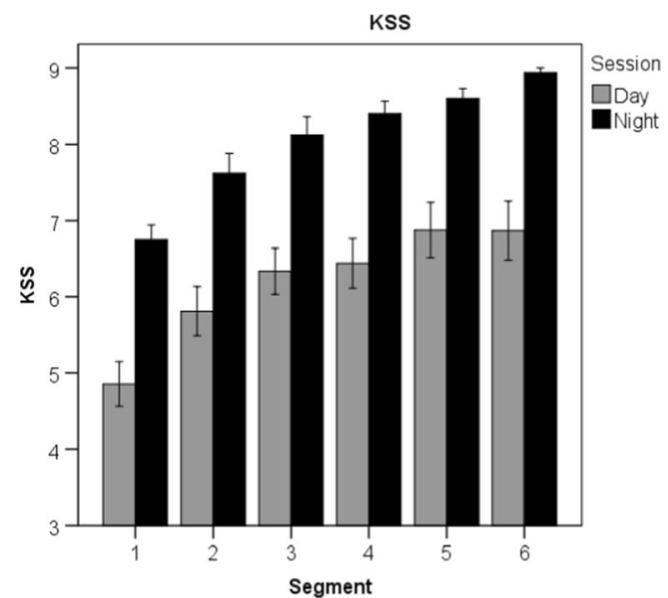

Fig. 2 Average Karolinska Sleepiness Scale, day and night for road segment along the road 1-6. Error bars represent Standard error of mean

The proportion of line crossings during the daytime and night-time while at KSS 9 was calculated. KSS 9 correspond to "very sleepy, great effort to keep alert fighting sleep" and has been proven to be correlated to performance impariments in different settings [25].

In addition, a variable grouping $0=$ average blink duration less than $0.15 \mathrm{~s}$ and $1=$ average blink duration longer than $0.15 \mathrm{~s}$ was used to compare the proportion of line crossings in relation to long blink durations. Fisher's exact test was used to test the probability that the proportions of two groups would vary between different categories. Furthermore, a logistic regression, entering all variables at the same time, was used to analyse the risk of line crossing to the left at different levels of KSS, blink durations, during different times of the day and at different segments. Observations with at least one line crossing within a road segment were coded as "ones" and observations without line crossings were coded as "zero". To avoid unbalance in self-reported sleepiness, KSS 1-5 were put into one group and KSS 6, KSS 7, KSS 8 finally KSS 9 were

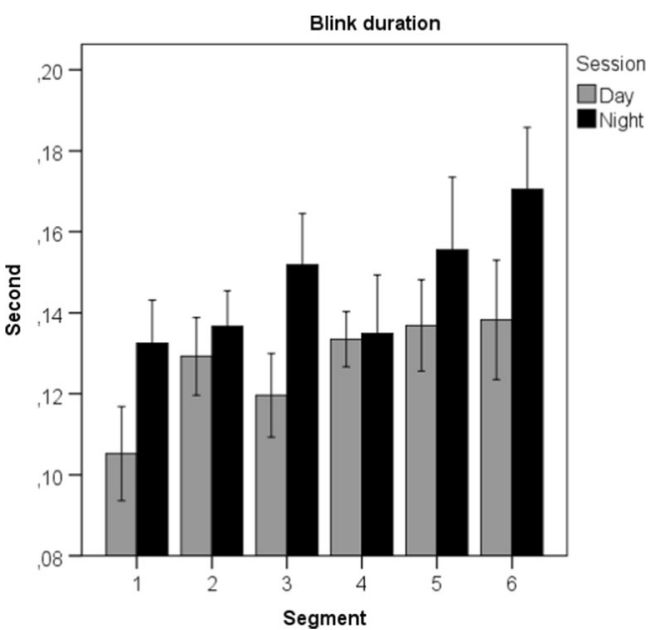

Fig. 3 Blink duration, day and night for road segment along the road 16. Error bars represent Standard error of mean 


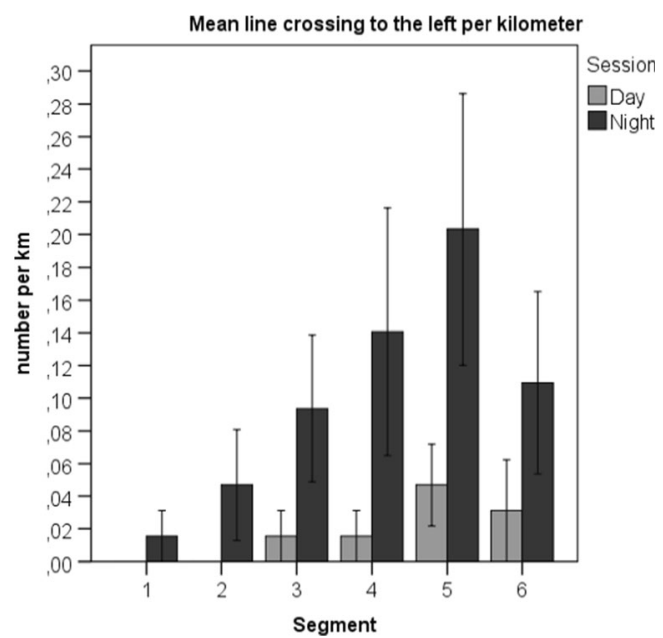

Fig. 4 Line crossings left, day and night for road segment 1-6 along the road. Error bars represent Standard error of mean

considered individually. Putting KSS $1-5$ into one group is motivated by the fact that these ratings are basically various degrees of alert, whereas KSS 6-9 corresponds to various levels of sleepiness.

\section{Result}

In total, there were 186 data points consisting of the total road segments observations for all participants (92 daytime and 94 night-time; referred to as observations). The difference between day and night is due to technical problems. In total, 26 observations (14\%) contained at least one line crossing. In total, the drivers reported KSS 1-5 (alert) in 35 cases (18\%), KSS 6 in 30 observations (16\%), KSS 7 in 36 observations (19\%), KSS 8 in 34 observations (18\%) and KSS 9 in 51 observations (27\%). There was a significant effect of time on task (road segment) $\mathrm{F}=29.03_{(5159)}(p<0.01)$, and of Session (day/night) $\mathrm{F}=264,8_{(1159)}(p<0.01)$ on KSS, see Fig. 2.

There was also a significant effect of time on task (road segment) $\mathrm{F}=3.9_{(5165)}(p<0.01)$, and of Session (day/night) $\mathrm{F}=15.9_{(1165)}(p<0.01)$ on Blink duration, see Fig. 3.

There was a significant effect of time on task (road segment) $\mathrm{F}=2.4_{(5165)}(p=0.04)$, and of Session (day/night)
$\mathrm{F}=14.6_{(1165)}(p<0.01)$ the average number of line crossings to the left, see Fig. 4.

There were no significant interactions between factors for any of the variables. For KSS (Wald $\mathrm{Z}=2.47 ; p=0.01$ ), Blink duration (Wald $\mathrm{Z}=2.54 p=0.01$ ) and line crossings (Wald $\mathrm{Z}=2.02 p=0.04$ ) there were significant differences between participants. In total, there were 51 observations with KSS 9 , see Table 3. For occurrences of KSS 9 during the day time 3 out of $9(33 \%)$ resulted in line crossings, during night time 17 out of $42(40 \%)$ resulted in line crossings. Fisher's test determining the probability that two groups proportions will end up in distinct categories was 0.28 . With the reservation for few observations in one cell the Chi-square test showed no statistical difference $\left(X^{2}=0.11\right)$.

When it comes to blink duration there were in total (regardless KSS level) 62 data points with long blink durations. In the day-time there were 25 data points with only 1 (4\%) containing a line crossings. During the night time, there were 37 data points with long blink durations of which $13(35 \%)$ resulted in line crossings, see Table 4 . Fishers' exact test was 0.003 . The difference between the prevalence of line crossings in the day and night time during observations with long blinks was significant $\left(X^{2}=134\right)$.

The correlation between KSS and Blink duration was 0.44 and significant $(p<0.01)$. The correlation between KSS and blink duration indicates that most of the line crossings occurred during high levels of KSS in combination with long blink duration during day time and night time, see Fig. 5.

The logistic regression analysis of the risk of line crossings to the left during day and night time shows that KSS was the only significant factor with an overall odds ratio (OR) of 5.4 for each KSS step increase using KSS 5 as reference, see Table 5.

\section{Discussion}

Among observations with only KSS 9, 33\% resulted in line crossings during daytime compared to $40 \%$ during the nighttime. According to Fisher's test, the likelihood is low that the number of line crossings at KSS $=9$ differs between daytime and night-time. In contrast, when the blink duration exceeded
Table 3 The number of line crossings during day and nighttime at different KSS levels. Percentages of observations distributed per KSS, separated for day/night, in brackets

\begin{tabular}{llllll}
\hline & \multicolumn{2}{l}{ Day } & & \multicolumn{2}{l}{ Night } \\
\cline { 2 - 3 } \cline { 5 - 6 } KSS & 0 line crossings & $\geq 1$ line crossing & & 0 line crossings & $\geq 1$ line crossing \\
\hline $1($ KSS 1-5) & $35(100)$ & 0 & 0 & 0 \\
$2($ KSS 6) & $20(100)$ & 0 & $10(100)$ & 0 \\
$2($ KSS 7) & $19(95)$ & $1(5)$ & & $16(100)$ & 0 \\
$3($ KSS 8) & $6(75)$ & $2(25)$ & $23(88)$ & $3(12)$ \\
$3($ KSS 9) & $6(67)$ & $3(33)$ & $25(60)$ & $17(40)$ \\
\hline
\end{tabular}


Table 4 Number of segments with at least one line crossing during day and night at different levels of blink duration. Percentages of observations distributed per blink duration group, separated for day/night

\begin{tabular}{llllll}
\hline & \multicolumn{1}{l}{ Day } & & \multicolumn{2}{l}{ Night } \\
\cline { 2 - 3 } \cline { 5 - 6 } Blink duration & 0 line crossing & $\geq 1$ line crossing & & 0 line crossing & $\geq 1$ line crossing \\
\hline$<0.15 \mathrm{~s}$ & $66(93)$ & $5(7)$ & $52(88)$ & $7(12)$ \\
$>0.15 \mathrm{~s}$ & $24(96)$ & $1(4)$ & $24(65)$ & $13(35)$ \\
\hline
\end{tabular}

$0.15 \mathrm{~s} 4 \%$ of the observations were accompanied by line crossings during daytime compared to $35 \%$ during night-time. In this case, the probability is high that there are more line crossings during night-time while having long blinks compared to daytime when blink duration is long. One explanation for the difference between the results for KSS and blink duration might be that the blink duration is more related to the biological process behind sleepiness while KSS is a subjective rating that reflects the general state of the driver [28]. Another reason that was suggested by Brown and colleagues already 50 years ago [29] is that normal driving is a task with a high degree of automation. Therefore, a sleepy driver may manage rather simple driving fairly well, despite the general functional capacity being clearly deteriorated. Thus, during simple and automated driving, as in this study, negative effects of sleepiness on driving performance will be difficult to observe by the drivers themselves and the difference in the objective sleepiness indicators at high level of self-reported sleepiness might be due to the drivers not understanding their own signs of sleepiness.

The results received in this pilot study also support the statement that countermeasures for driver fatigue need to consider the reason behind [30]. . It is well known that humans are influenced by the time of the day. The Three Process Model has been shown to predict crashes with a high sensitivity [31]. Taking this into account there is need, to not only look at a specific indicator, but also consider that it might tell us different things about the criticality depending on the factor, time of

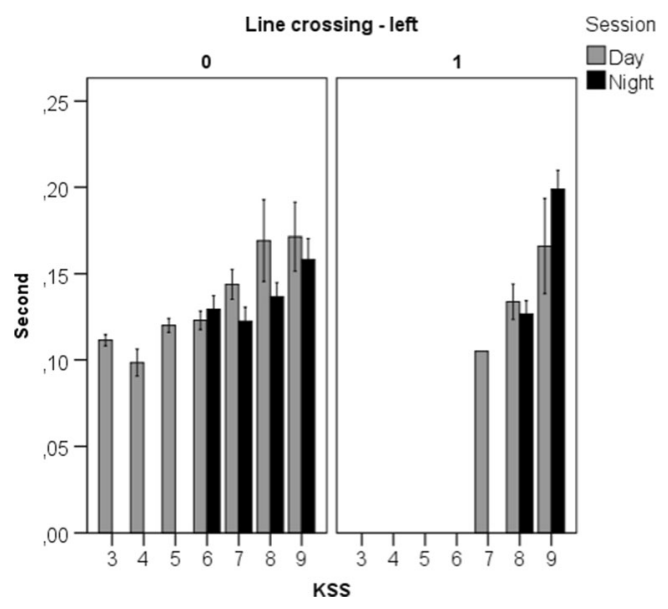

Fig. 5 Line crossings to the left $(0=0$ line crossings; $1=\geq 1$ line crossing), day and night for Karolinska sleepiness Scale in relation to blink duration. Error bars represent Standard error of mean the day. This multidimensional approach is also supported by the literature showing that fusion of indicators, in our case KSS, Blink duration and time of the day, provides a better detection of driver sleepiness [32, 33].

KSS increased with time on task and blink duration was longer with time on task, this is in line with earlier research [34, 35]. Our results indicate that future development and improvements of driver support systems may use different criteria's or thresholds for activations of warnings day time compare to night time if the aim is to avoid critical situations.

When looking at the risk for line crossings with help of regression, the only significant predictor was KSS (OR 5.4). Further, there was no significant difference in the proportion of line crossings between day and night during high levels of $\mathrm{KSS}$, suggesting that a driver experiencing high levels needs to be aware of their increased risk regardless of the time of day. The reason for that time of the day is not included in the final model, might be due to that day or night per se is not enough information to explain the line crossing. Our results indicate that future development and improvements of driver support systems might use different strategies to convince a driver to counteract depending on the time of the day with more efforts addressed to the driver during night time.

The current study suffers from several limitations. The most important is the confounding effect of alert drivers during daytime versus sleep deprived drivers during night-time. In addition there might be a risk that the drivers results differ depending on if they were the first or second driver during the day or night. Ideally, the study should have been balanced with regard to day-time versus night-time and with regard to alert versus sleep deprived. For example, there should have been alert drivers during night-time and sleep deprived drivers during daytime. An implication is that there were very few observations with high levels of sleepiness and line crossings during daytime. Another limitation is that a day-light scenario

Table 5 Logistic regression for line crossings - OR for KSS, Session (day/night), Road segment and blink duration

\begin{tabular}{llll}
\hline Segment & Odds ratio & $95 \%$ CI & $p$-value \\
\hline KSS & $\mathbf{5 . 4 3}$ & $\mathbf{2 . 4 1 - 1 2 . 2 5}$ & $<\mathbf{0 . 0 1}$ \\
Session & 0.75 & $0.23-2.46$ & 0.63 \\
Road segment & 0.88 & $0.62-1.25$ & 0.48 \\
Blink duration & 1.09 & $0.41-2-89$ & 0.87 \\
\hline
\end{tabular}


was used in the simulator for both the day and night condition. On one hand, this removes confounding effects of light versus dark, but on the other hand, light conditions are an important property that defines day and night. In addition, there were, as in most studies of sleepiness, big differences between individuals [36].

\section{Conclusion}

In conclusion, the results do not support the hypothesis that high levels of KSS will result in more line crossings at night time compared to day time. However, the result supports the hypothesis that long blink durations are associated with more line crossings when they appear during night time than during daytime. In general time of the day was not a significant predictor of line crossings, only KSS was a significant predictor with an OR of 5.4.

Acknowledgements This study was possible to do thanks to funding's from the competence centres ViP and Safer (the Vehicle and Traffic Safety Centre at Chalmers). We also would like to thank all the participants that drove day and night in the simulator.

Open Access This article is distributed under the terms of the Creative Commons Attribution 4.0 International License (http:// creativecommons.org/licenses/by/4.0/), which permits unrestricted use, distribution, and reproduction in any medium, provided you give appropriate credit to the original author(s) and the source, provide a link to the Creative Commons license, and indicate if changes were made.

\section{References}

1. Connor J, Norton R, Ameratunga S, Robinson E, Civil I, Dunn R, Bailey J, Jackson R (2002) Driver sleepiness and risk of serious injury to car occupants: population based case control study. BMJ 324(7346):1125-1128A

2. Horne J, Reyner L (1995) Driver sleepiness. J Sleep Res 4(2):23-29

3. Stutts J, Wilkins J, Scott O, Vaughn B (2003) Driver risk factors for sleep-related crashes. Accid Anal and Prev 35(3):321-331. doi:10. 1016/s0001-4575(02)00007-6

4. Åkerstedt T, Kecklund G (2001) Age, gender and early morning highway accidents. J Sleep Res 10(2):105-110. doi:10.1046/j. 1365-2869.2001.00248.x

5. Filtness AJ, Reyner LA, Horne JA (2012) Driver sleepinesscomparisons between young and older men during a monotonous afternoon simulated drive. Biol Psychol 89(3):580-583. doi:10. 1016/j.biopsycho.2012.01.002

6. Lowden A, Anund A, Kecklund G, Peters B, Akerstedt T (2009) Wakefulness in young and elderly subjects driving at night in a car simulator. Accid Anal and Prev 41(5):1001-1007. doi:10.1016/j. aap.2009.05.014

7. Hanowski R, Hickman J, Wierwille W, Keisler A (2007) A descriptive analysis of light vehicle-heavy vehicle interactions using in situ driving data. Accid Anal and Prev 39(1):169-179

8. Hanowski R, Wierwille W, Dingus T (2003) An on-road study to investigate fatigue in local/short haul trucking. Accid Anal and Prev 35(2):153-160
9. Klauer S, Dingus T, Neale V, Sudweeks J, Ramsey D (2006) The impact of driver inattention on near-crash/crash risk: an analysis using the 100-car naturalistic driving study data. NHTSA, Washington DC

10. Ftouni S, Sletten T, Howard M, Anderson C, Lenné M, Lockley S, Rajaratnam S (2013) Objective and subjective measures of sleepiness, and their associations with on-road driving events in shift workers. J Sleep Res 22(1):58-69. doi:10.1111/j.1365-2869.2012.01038.x

11. Åkerstedt T, Peters B, Anund A, Kecklund G (2005) Impaired alertness and performance driving home from the night shift: a driving simulator study. J Sleep Res 14:17-20

12. Philip P, Taillard J, Sagaspe P, Boussuge J, Chaumet G, QueraSalva M, Leger D, Bioulac B, Virginie B (2009) Sleep disorders, sleepiness at the wheel and driving accident risk. Sleep 32:248-248

13. Åkerstedt T, Hallvig D, Anund A, Fors C, Schwarz J, Kecklund G (2013) Having to stop driving at night because of dangerous sleepiness - awareness, physiology and behaviour. J Sleep Res. doi:10. 1111/jsr.12042

14. May J, Baldwin C (2009) Driver fatigue: the importance of identifying causal factors of fatigue when considering detection and countermeasure technologies. Transp Res F 12(3):218-224. doi: 10.1016/j.trf.2008.11.005

15. Czeisler C, Gooley J (2007) Sleep and circadian rhythms in humans. Cold Spring Harb Symp Quant Biol 72:579-597. doi:10. 1101/sqb.2007.72.064

16. Åkerstedt T, Connor J, Gray A, Kecklund G (2008) Predicting road crashes from a mathematical model of alertness regulation - the sleep/wake predictor. Accid Anal and Prev 40(4):1480-1485

17. Di Milia L, Smolensky M, Costa G, Howarth H, Ohayon M, Philip P (2011) Demographic factors, fatigue, and driving accidents: an examination of the published literature. Accid Anal and Prev 43(2): 516-532. doi:10.1016/j.aap.2009.12.018

18. Hallvig D, Anund A, Fors C, Kecklund G, Karlsson J, Wahde M, Akkerstedt T (2013) Sleepy driving on the real road and in the simulator-a comparison. Accid Anal and Prev 50 (journal article): 44-50. doi:10.1016/j.aap.2012.09.033

19. Otmani S, Pebayle T, Roge J, Muzet A (2005) Effect of driving duration and partial sleep deprivation on subsequent alertness and performance of car drivers. Physiol Behav 84(5):715-724. doi:10. 1016/j.physbeh.2005.02.021

20. Philip P, Sagaspe P, Moore N, Taillard J, Charles A, Guilleminault C, Bioulac B (2005) Fatigue, sleep restriction and driving performance. Accid Anal and Prev 37(3):473-478. doi:10.1016/j.aap. 2004.07.007

21. Matthews RW, Ferguson SA, Zhou X, Kosmadopoulos A, Kennaway DJ, Roach GD (2012) Simulated driving under the influence of extended wake, time of day and sleep restriction. Accid Anal Prev 45(Suppl):55-61. doi:10.1016/j.aap.2011.09.027

22. Hallvig D, Anund A, Fors C, Kecklund G, Åkerstedt T (2014) Real driving at night - predicting lane departures from physiological and subjective sleepiness. Biol Psychol 101(1):18-23. doi:10.1016/j. biopsycho.2014.07.001

23. Horne JA, Reyner LA, Barrett PR (2003) Driving impairment due to sleepiness is exacerbated by low alcohol intake. Occup Environ Med 60(9):689-692

24. Åkerstedt T, Gillberg M (1990) Subjective and objective sleepiness in the active individual. Int J Neurosi 52:29-37

25. Åkerstedt T, Anund A, Axelsson J, Kecklund G (2014) Subjective sleepiness is a sensitive indicator of insufficient sleep and impaired waking function. J Sleep Res 23(3):240-252. doi:10.1111/jsr.12158

26. Schleicher R, Galley N, Briest S, Galley L (2008) Blinks and saccades as indicators of fatigue in sleepiness warnings: looking tired? Ergonomics 51(7):982-1010. doi:10.1080/00140130701817062

27. James B, Sharabaty H, Esteve D (2008) A first step toward automatic drowsiness scoring during wake-sleep transitions. Somnologie 12:227-232 
28. Åkerstedt T, Gillberg M (1990) Subjective and objective sleepiness in the active individual. Int J Neurosci 52:29-37

29. Brown ID (1962) Measuring the "spare mental capacity" of car drivers by subsidary audatory task. Ergonomics 5:247-250

30. May JF, Baldwin CL (2009) Driver fatigue: the importance of identifying causal factors of fatigue when considering detection and countermeasure technologies. Transp Res F Psychol Behav 12(3): 218-224. doi:10.1016/j.trf.2008.11.005

31. Åkerstedt T, Connor J, Gray A, Kecklund G (2008) Predicting road crashes from a mathematical model of alertness regulation - the sleep/wake predictor. Accid Anal Prev. doi:10.1016/j.aap.2008.03. 016

32. Dawson D, Searle A, Paterson J (2014) Look before you (s)leep: evaluating the use of fatigue detection technologies within a fatigue risk management system for the road transport industry. Medicine Reviews 18:141-152
33. Hallvig D, Anund A, Fors C, Kecklund G, Akerstedt T (2014) Real driving at night-predicting lane departures from physiological and subjective sleepiness. Biol Psychol 101:18-23. doi:10.1016/j. biopsycho.2014.07.001

34. Sandberg D, Åkerstedt T, Anund A, Kecklund G, Wahde M (2011) Detecting driver sleepiness using optimized nonlinear combinations of sleepiness indicators. IEEE Trans Intell Transp Syst 12(1):97108

35. Åkerstedt $\mathrm{T}$, Ingre $\mathrm{M}$, Kecklund $\mathrm{G}$, Anund $\mathrm{A}$, Sandberg D, Wahde M, Philip P, Kronberg P (2010) Reactions of sleepiness indicators to partial sleep deprivation, time of day and time on task in a driving simulator - the DROWSI project. J Sleep Res 19(2):298-309

36. Ingre M, Åkerstedt T, Peters B, Anund A, Kecklund G (2006) Subjective sleepiness, simulated driving performance and blink duration: examining individual differences. J Sleep Res 15(1):47-53 